\title{
Incidence of clinical fractures: A 7-year follow-up study in institutionalized adults with epilepsy and intellectual disability
}

Citation for published version (APA):

Berkvens, J. J. L., Wyers, C. E., Mergler, S., Beerhorst, K., Verschuure, P., Tan, I. Y., Majoie, H. J. M., \& van den Bergh, J. P. W. (2021). Incidence of clinical fractures: A 7-year follow-up study in institutionalized adults with epilepsy and intellectual disability. SEIZURE-EUROPEAN JOURNAL OF EPILEPSY, 92, 5661. https://doi.org/10.1016/j.seizure.2021.08.009

Document status and date:

Published: 01/11/2021

DOI:

10.1016/j.seizure.2021.08.009

Document Version:

Publisher's PDF, also known as Version of record

\section{Document license:}

Taverne

Please check the document version of this publication:

- A submitted manuscript is the version of the article upon submission and before peer-review. There can be important differences between the submitted version and the official published version of record.

People interested in the research are advised to contact the author for the final version of the publication, or visit the DOI to the publisher's website.

- The final author version and the galley proof are versions of the publication after peer review.

- The final published version features the final layout of the paper including the volume, issue and page numbers.

Link to publication

\footnotetext{
General rights rights.

- You may freely distribute the URL identifying the publication in the public portal. please follow below link for the End User Agreement:

www.umlib.nl/taverne-license

Take down policy

If you believe that this document breaches copyright please contact us at:

repository@maastrichtuniversity.nl

providing details and we will investigate your claim.
}

Copyright and moral rights for the publications made accessible in the public portal are retained by the authors and/or other copyright owners and it is a condition of accessing publications that users recognise and abide by the legal requirements associated with these

- Users may download and print one copy of any publication from the public portal for the purpose of private study or research.

- You may not further distribute the material or use it for any profit-making activity or commercial gain

If the publication is distributed under the terms of Article $25 \mathrm{fa}$ of the Dutch Copyright Act, indicated by the "Taverne" license above, 


\title{
Incidence of clinical fractures: A 7-year follow-up study in institutionalized adults with epilepsy and intellectual disability
}

\author{
J.J.L. Berkvens ${ }^{\text {a, }}$, C.E. Wyers ${ }^{\mathrm{b}, \mathrm{c}}$, S. Mergler ${ }^{\mathrm{d}, \mathrm{e}}$, K. Beerhorst ${ }^{\mathrm{f}}$, P. Verschuure $^{\mathrm{g}}$, I.Y. Tan ${ }^{\mathrm{a}}$, H.J. \\ M. Majoie ${ }^{\text {h,i,j }}$, J.P.W. van den Bergh ${ }^{\text {b,c }}$ \\ ${ }^{a}$ Department of Residential Care, Epilepsy Center Kempenhaeghe, Heeze, The Netherlands \\ ${ }^{\mathrm{b}}$ Department of Internal Medicine, VieCuri Medical Center, Venlo, The Netherlands \\ ${ }^{\mathrm{c}}$ NUTRIM School of Nutrition and Translational Research in Metabolism, Department of Internal Medicine, Maastricht University Medical Center, Maastricht, The \\ Netherlands \\ ${ }^{\mathrm{d}}$ Medical Department ASVZ, Care and Service Center for People with Intellectual Disabilities, Sliedrecht, The Netherlands \\ ${ }^{\mathrm{e}}$ Department of General Practice and Intellectual Disability Medicine, Erasmus University Medical Center, Rotterdam, The Netherlands \\ ${ }^{\mathrm{f}}$ Department of Neurology, Zuyderland Medical Center, Heerlen, The Netherlands \\ ${ }^{g}$ Laboratory for Clinical Chemistry \& Pharmacology, Epilepsy Center Kempenhaeghe, Heeze, The Netherlands \\ ${ }^{\mathrm{h}}$ Department of Neurology, Academic Center for Epileptology Kempenhaeghe and Maastricht University Medical Center, Heeze and Maastricht, The Netherlands \\ ${ }^{\mathrm{i}}$ MHeNs School for Mental Health and Neuroscience, Department of Psychiatry and Neuropsychology, Maastricht University Medical Center, Maastricht, The Netherlands \\ ${ }^{\mathrm{j}}$ School of Health Professions Education, Faculty of Health, Medicine and Life Sciences, Maastricht University, Maastricht, the Netherlands
}

\section{A R T I C L E I N F O}

\section{Keywords:}

Epilepsy

Intellectual disability

Antiseizure drugs (ASD)

Bone mineral density (BMD)

Fractures

\begin{abstract}
A B S T R A C T
Purpose: To determine the incidence of clinical fractures over seven years of follow-up, in adults with epilepsy and intellectual disability, residing in a long-stay care facility.

Methods: In 2009, all institutionalized adult patients $(n=261)$ were invited to undergo a Dual-energy X-ray Absorptiometry (DXA) measurement and a Vertebral Fracture Assessment (VFA). Participants were followed over seven years or until date of discharge (in case of moving from the care facility) or date of death. The patients' medical files were screened for radiology reports and staff notes, to identify clinical fractures. Fracture incidence rates (IR) were determined and compared for subgroups, by calculating incidence rate ratios. Hazard ratios were calculated to identify factors associated with fracture risk, using Cox Proportional Hazards analyses.

Results: A total of 205 patients (124 male, 60.5\%) aged between 18 and 88 years (median 48, IQR 34-60) were enrolled. At baseline, 92 patients (44.9\%) were diagnosed with osteopenia and 65 (31.7\%) with osteoporosis. Between 2009 and 2016, 30 patients (14.6\%) deceased and 3 patients (1.5\%) left the care facility. During followup, 156 clinical fractures were reported in 82 patients (40.0\%). Thirty-eight patients (18.5\%) had at least one major osteoporotic fracture. Overall, the IR was 11.6 fractures per 100 person-years. Fracture risk was significantly lower in patients who were wheelchair dependent than in patients who were able to walk $(p<.001)$. Conclusion: This study demonstrated that $40 \%$ of institutionalized adults with epilepsy and intellectual disability had at least one clinical fracture during seven years of follow-up, despite adequate anti-osteoporosis treatment.
\end{abstract}

\begin{tabular}{|c|c|c|c|}
\hline \multirow{3}{*}{\multicolumn{2}{|c|}{ Abbreviations }} & FN & Femoral neck \\
\hline & & HR & Hazard ratio \\
\hline & & IR & Incidence rate \\
\hline ASD & Antiseizure drugs & IRR & Incidence rate ratio \\
\hline BMD & Bone mineral density & IQ & Intelligence quotient \\
\hline BMI & Body mass index & IQR & Interquartile range \\
\hline BP & Bisphosphonates & MOF & Major osteoporotic fracture \\
\hline $\mathrm{CI}$ & Confidence interval & P-Ys & Person-years \\
\hline DXA & Dual-energy X-ray Absorptiometry & & \\
\hline
\end{tabular}

\footnotetext{
* Corresponding author: Department of Residential Care, Epilepsy Center Kempenhaeghe, P.O. Box 61, 5590 AB Heeze, The Netherlands.

E-mail address: BerkvensJ@Kempenhaeghe.nl (J.J.L. Berkvens).
} 
SD Standard deviation

VFA Vertebral Fracture Assessment

VF Vertebral fracture

\section{Introduction}

Epilepsy is a chronic, neurological disorder characterized by recurrent seizures, affecting approximately $0.4-1.0 \%$ of the global population. In the majority of the patients, seizures can be successfully controlled with antiseizure drugs [1]. In about $30 \%$ of the patients, the seizures remain refractory. Despite benefits of antiseizure treatment (decrease in number and/or severity of seizures), chronic use of antiseizure drugs is known to affect bone health, which was first reported around 1970 [2-4]. Since then, meta-analyses including multiple studies, have shown an association between the use of antiseizure drugs and an increased fracture risk [5,6]. Most of the studies included ambulatory, independently-living adults with epilepsy. In institutionalized patients, fracture rates might even be higher, as they are more likely to suffer from severe comorbidities, refractory seizures and fall-related incidents. In addition, a poor nutritional status, a lack of sunlight exposure and immobility have been shown to be related to a low bone mineral density (BMD) [7-10]. Studies regarding clinical fractures and fracture risks in institutionalized adult patients on chronic antiseizure drugs are of older age and mostly limited to the use of phenobarbital and phenytoin [11-14].

Therefore, the main objective of this study is to determine the incidence of fractures over seven years of follow-up, in adults with epilepsy and intellectual disability, residing in a long-stay care facility.

\section{Material and methods}

\subsection{Study population}

This retrospective cohort study was performed at the long-stay care department of Epilepsy Center Kempenhaeghe, a tertiary care facility for people with epilepsy in the Netherlands. All patients had a diagnosis of epilepsy, caused by structural, genetic, infectious, metabolic, immune or unknown factors and most of the patients (99.0\%) had a degree of intellectual disability (mild, moderate, severe or profound).

In 2009, all 261 adult patients (aged 18 years or older) were asked to participate in a study regarding bone status (METC: NL26095.068.09) $[15,16]$. Forty-seven patients (or their legal representatives) declined the invitation and nine patients (or their legal representatives) did not respond. A total of 205 patients (or their legal representatives) gave informed consent (78.5\%) and were included in the study. No further inor exclusion criteria were applied.

\subsection{Study design and data collection}

In 2009, all participants had a bone mineral density measurement using dual-energy X-ray absorptiometry (DXA) with vertebral fracture assessment (VFA) (Hologic Discovery W/A). BMD was expressed in $\mathrm{g} /$ $\mathrm{cm}^{2}$ and T-scores. A T-score is the number of standard deviations (SD) below peak bone mass, according to the manufacturer's reference database. DXA is the gold standard for diagnosing a normal bone density (a T-score $\geq-1.0 \mathrm{SD}$ ), osteopenia (a T-score of -1.0 to $-2.5 \mathrm{SD}$ ) and osteoporosis (a T-score $\leq-2.5 \mathrm{SD}$ ) as defined by the World Health Organization [17].

For each individual in this study, data collection started on the day of the DXA scan (between August 31st and September 29th, 2009) and ended after seven years of follow-up (between October 5th and November 30th, 2016). When a patient deceased, or left the care facility during the study period, data collection was stopped on the day of death or discharge. The patients' medical files at the care facility and the radiology reports of the hospital patients were referred to, were screened to extract clinical fractures. In addition, fracture-related search terms (i. e. '\#', 'breuk', 'gebroken', 'fractu“') were used to screen notes and documents from nursing staff and general practitioners. All clinical (symptomatic) fractures were classified according to the ICD-10. Major osteoporotic fractures (MOF) were defined as: fractures of proximal humerus (S42.2-S42.4), forearm (S52), hip (S72.0-S72.2) and vertebrae (S12, S22.0-S22.1, S32.0-S32.2, S32.7-S32.8) [18]. In this study, we only included symptomatic vertebral fractures (VFs). Asymptomatic prevalent vertebral fractures (as diagnosed by VFA) in our study population were previously reported [19]. Of the 184 patients with a VFA at baseline, 77 (41.8\%) were diagnosed with a prevalent vertebral fracture.

Patient characteristics (age, sex, length, weight, intellectual disability and ambulatory status) and (history of) medication use (antiseizure drugs, calcium, and vitamin D supplements and bisphosphonates) were extracted from the patients' medical files. Patients were treated with calcium and vitamin $\mathrm{D}$ and additionally with bisphosphonate (BP) therapy (oral or intravenous) in case of osteoporosis or a vertebral fracture grade two or three, according to the Dutch guideline at that time $[20,21]$. None of the patients received denosumab, strontium ranelate, raloxifene, teriparatide, or recombinant parathyroid hormone (PTH). All medication (including supplementation of calcium and vitamin D) was administered by nurses and/or taken under direct supervision.

\subsection{Statistical analysis}

The primary outcome of this study is the incidence of clinical fractures over seven years follow-up. Data are presented as means ( $\pm \mathrm{SD}$ ), medians (interquartile range, IQR), or frequencies (percentages). Differences between patients with and without complete follow-up were analyzed using Student's $t$-test (parametric) or Mann-Whitney $U$-test (nonparametric) for continuous variables, and Pearson's Chi-Square test for categorical variables. The incidence rate (IR) was calculated as the total number of clinical fractures during follow-up, divided by the sum of each patients' time at risk. Fracture incidence rates for subgroups were compared by calculating incidence rate ratios (IRR) using $R$ version 4.0.3 (The R Foundation for Statistical Computing, Austria). Hazard ratios (HR) were calculated to identify factors associated with fracture risk, using Cox Proportional Hazards analyses. All outcomes were analyzed using SPSS version 27 (IBM Corporation, UK) and statistical tests were two-tailed with a level of significance of 0.05 .

\section{Results}

\subsection{Study population}

A total of 205 patients (124 male, 60.5\%) aged between $18-88$ years (median 48, IQR 34-60) were enrolled in the study. Duration of followup ranged from 1 to 87 months (median 85.3, IQR 84.7-85.9). Baseline characteristics are shown in Table 1.

\subsection{Antiseizure drugs}

At baseline, 150 patients (73.2\%) used both enzyme-inducing and non-enzyme-inducing drugs. During follow-up, 103 patients (50.2\%) had a switch in prescribed antiseizure drugs; 78 patients (38.0\%) started at least one other antiseizure drug and 75 patients (36.6\%) stopped at least one antiseizure drug they were using at baseline. Twenty-eight patients (13.7\%) stopped at least one enzyme-inducing drug (12 carbamazepine, 9 phenytoin, 2 phenobarbital, 2 oxcarbazepine, 1 topiramate and 2 phenytoin+topiramate) and four patients $(2.0 \%)$ switched from one enzyme-inducing drug to another enzyme-inducing drug. In addition, six patients (2.9\%) started an enzyme-inducing drug (3 phenytoin, 1 carbamazepine, 1 oxcarbazepine, 1 topiramate). Further, a total of 169,028 epileptic seizures (median 275 seizures per patient during follow-up, IQR 55-1060) were reported. Half of the patients $(47.3 \%)$ had one or more seizures a week. 
Table 1

Baseline characteristics (in 2009) of 205 patients with refractory epilepsy and intellectual disability.

\begin{tabular}{|c|c|c|}
\hline & n (\%) & Median (IQR) \\
\hline \multicolumn{3}{|l|}{ Sex } \\
\hline Male & $124(60.5)$ & \\
\hline Female & $81(39.5)$ & \\
\hline Age (in years) & 205 & $48(34-60)$ \\
\hline \multicolumn{3}{|l|}{ Intellectual disability } \\
\hline None $(I Q \geq 70)$ & $2(1.0)$ & \\
\hline Mild (IQ 55-70) & $56(27.3)$ & \\
\hline Moderate (IQ 40-55) & $72(35.1)$ & \\
\hline Severe (IQ 25-40) & $61(29.8)$ & \\
\hline Profound (IQ < 25) & $14(6.8)$ & \\
\hline \multicolumn{3}{|l|}{ Ambulatory status } \\
\hline Wheelchair dependent & $58(28.3)$ & \\
\hline Walk with aid & $25(12.2)$ & \\
\hline Walk without aid & $122(59.5)$ & \\
\hline \multicolumn{3}{|l|}{ Body Mass Index } \\
\hline Underweight $(<18.5)$ & $7(3.4)$ & \\
\hline Normal weight (18.5-25) & $96(46.8)$ & \\
\hline Overweight (25-30) & $73(35.6)$ & \\
\hline Obese $(\geq 30)$ & $29(14.1)$ & \\
\hline Number of antiseizure drugs & & $3(2-4)$ \\
\hline None & $8(3.9)$ & \\
\hline One & $16(7.8)$ & \\
\hline Two & $42(20.5)$ & \\
\hline Three & $78(38.0)$ & \\
\hline Four & $54(26.3)$ & \\
\hline Five & $3(1.5)$ & \\
\hline Six & $4(2.0)$ & \\
\hline Enzyme-inducing* & $171(83.4)$ & \\
\hline Strong; Carbamazepine & $123(60.0)$ & \\
\hline Phenobarbital & $21(10.2)$ & \\
\hline Phenytoin & $45(22.0)$ & \\
\hline Weak; Oxcarbazepine & $27(13.2)$ & \\
\hline Topiramate & $28(13.7)$ & \\
\hline Non-enzyme-inducing* & $176(85.9)$ & \\
\hline Acetazolamide & $1(0.5)$ & \\
\hline Clobazam & $81(39.5)$ & \\
\hline Clonazepam & $34(16.6)$ & \\
\hline Ethosuximide & $4(2.0)$ & \\
\hline Felbamate & $1(0.5)$ & \\
\hline Gabapentin & $9(4.4)$ & \\
\hline Lacosamide & $1(0.5)$ & \\
\hline Lamotrigine & $76(37.1)$ & \\
\hline Levetiracetam & $40(19.5)$ & \\
\hline Pregabalin & $6(2.9)$ & \\
\hline Valproic acid & $88(42.9)$ & \\
\hline Vigabatrin & $1(0.5)$ & \\
\hline Zonisamide & $3(1.5)$ & \\
\hline \multicolumn{3}{|l|}{ Seizure frequency } \\
\hline None & $21(10.2)$ & \\
\hline Less than 1 a year & $10(4.9)$ & \\
\hline 1 a month to 1 a year & $28(13.7)$ & \\
\hline 1 a week to 1 a month & $49(23.9)$ & \\
\hline 1 a day to 1 a week & $80(39.0)$ & \\
\hline More than 1 a day & $17(8.3)$ & \\
\hline
\end{tabular}

IQ = Intelligence quotient, IQR = Interquartile Range *Due to polytherapy and/ or the use of both enzyme- and non-enzyme-inducing antiseizure drugs, total numbers add up to more than $100 \%$.

\subsection{Bone mineral density and treatment}

In 2009, all patients underwent a DXA scan. In ten patients (4.9\%) the scan failed due to physical impairments $(n=4)$, lack of cooperation $(n=4)$ or the inability to lie still $(n=2)$. Ninety-two patients $(44.9 \%)$ were diagnosed with osteopenia and $65(31.7 \%)$ with osteoporosis. The remaining 38 patients $(18.5 \%)$ had a normal BMD.

At baseline, 22 patients (10.7\%) used calcium supplementation, 11 patients $(5.4 \%)$ vitamin D and 14 patients $(6.8 \%)$ had a combination of calcium and vitamin D.

Forty-two patients (20.5\%) already received bisphosphonate therapy at the start of the study and in 41 patients $(20.0 \%)$ treatment with anti- osteoporosis medication was initiated during the follow-up period.

\subsection{Clinical fractures}

Between 2009 and 2016, 82 patients (40.0\%) sustained 156 clinical fractures, of whom 38 (18.5\%) had at least one MOF (16 hip, 16 vertebrae, 9 forearm and 5 proximal humerus). Details on individual fracture sites are shown in Table 2. Seventy-one fractures (45.5\%) were reported after a fall and at least 39 fractures $(25.0 \%)$ were caused by a seizure; between $0.02-0.1 \%$ of the reported seizures led to a fracture.

Eight fractures $(5.1 \%)$ were caused by an accident or trauma and three fractures (1.9\%) had been reported to occur spontaneously. For the remaining 35 fractures (22.4\%), the circumstances were not reported in the medical records. The median time to the first fracture was 33.5 months (IQR 18.4-54.1).

Total person-time in this study was 1342.8 years, leading to an IR of 11.6 fractures per 100 person-years, or one fracture every 8.6 personyears. In Table 3 the IRRs for subgroups are shown. The IR was significantly lower in patients who were wheelchair dependent than in patients who were able to walk $(p<.001)$. The IR was significantly higher in patients diagnosed with osteoporosis vs patients with normal BMD ( $p$ $=.004$ ) and during bisphosphonate therapy vs not during therapy ( $p=$ $.003)$.

After adjustment for age, sex, femoral neck BMD, prevalent VF and seizure frequency (Table 4), mobility was the only factor that remained significantly associated with fracture risk with a lower risk (HR 0.32, [95\% CI 0.16-0.64], $p<.001$ ) in wheelchair dependent patients.

\subsection{Lost to follow-up}

Between 2009 and 2016, 30 patients (14.6\%) deceased and 3 patients $(1.5 \%)$ left the facility. Patients who deceased were significantly older $(p<.001)$ than patients who completed follow-up and had a significant lower BMD of femoral neck and total hip $(p<.01)$. No significant differences were found between the two groups, regarding BMD of lumbar spine $(p=.339)$, sex $(p=.651)$, BMI $(p=.876)$, ambulatory status $(p=.055)$, prescribed number of antiseizure drugs $(p=.206)$ or prevalent vertebral fractures $(p=.605)$ at baseline.

Table 2

Clinical fractures and fracture locations in patients with refractory epilepsy and intellectual disability $(n=205)$.

\begin{tabular}{lll}
\hline Fractures & Patients (\%) & \\
\hline None & $123(60.0)$ & \\
1 & $50(24.4)$ & \\
2 & $10(4.9)$ & \\
3 & $11(5.4)$ & \\
4 & $7(3.4)$ & \\
5 & $3(1.5)$ & \\
10 & $1(0.5)$ & \\
MOF & Patients (\%) & \\
None & $167(81.5)$ & Fractures (\%) \\
1 & $31(15.1)$ & $9(5.8)$ \\
2 & $6(2.9)$ & $3(1.9)$ \\
3 & $1(0.5)$ & $13(8.3)$ \\
ICD-10 & Fracture location & $7(4.5)$ \\
S02.0-S02.9 & Skull / facial bones & $31(19.9)$ \\
S12.0-S12.9 & Neck & $9(5.8)$ \\
S22.0-S22.9 & Rib(s) / sternum / thoracic vertebrae & $15(9.6)$ \\
S32.0-S32.8 & Lumbar vertebrae / pelvis & $17(10.9)$ \\
S42.0-S42.9 & Shoulder / upper arm & $33(21.2)$ \\
S52.0-S52.9 & Forearm & $19(12.2)$ \\
S62.0-S62.8 & Wrist / hand & \\
S72.0-S72.9 & Femur & \\
S82.0-S82.9 & Lower leg (incl. ankle) & \\
S92.0-S92.9 & Foot & \\
Total & $156(100.0)$ & \\
\hline
\end{tabular}

$\mathrm{MOF}=$ Major osteoporotic fracture. 
Table 3

Fracture incidence rates (IR) per subgroup and incidence rate ratios (IRR) for comparisons between subgroups.

\begin{tabular}{|c|c|c|c|c|c|c|c|}
\hline & Subgroup & N Patients & $\mathrm{N}$ Fractures & P-Ys & IR per $100 \mathrm{P}$-Ys & IRR $(95 \% \mathrm{CI})$ & $P$ \\
\hline \multirow[t]{2}{*}{ Sex } & Male & 124 & 97 & 812.6 & 11.9 & - & \\
\hline & Female & 81 & 59 & 530.2 & 11.1 & $0.93(0.67-1.29)$ & .671 \\
\hline \multirow[t]{2}{*}{ Age } & $18-49$ years & 112 & 85 & 764.7 & 11.1 & - & \\
\hline & $\geq 50$ years & 93 & 71 & 578.1 & 12.3 & $1.10(0.81-1.51)$ & .535 \\
\hline \multirow[t]{2}{*}{ Mobility } & Able to walk & 147 & 142 & 966.4 & 14.7 & - & \\
\hline & Wheelchair dependent & 58 & 14 & 376.3 & 3.7 & $0.25(0.15-0.44)$ & $<.001^{* *}$ \\
\hline \multirow[t]{4}{*}{ BMI category } & Underweight & 7 & 2 & 41.0 & 4.9 & $0.39(0.10-1.58)$ & .172 \\
\hline & Normal weight & 96 & 79 & 631.4 & 12.5 & - & .892 \\
\hline & Overweight & 73 & 61 & 476.4 & 12.8 & $1.02(0.73-1.43)$ & .055 \\
\hline & Obese & 29 & 14 & 193.9 & 7.2 & $0.58(0.33-1.02)$ & \\
\hline \multirow[t]{4}{*}{ Diagnosis (at baseline) } & Normal BMD & 38 & 20 & 250.0 & 8.0 & - & \\
\hline & Osteopenia & 92 & 65 & & 10.9 & $1.36(0.83-2.25)$ & .223 \\
\hline & Osteoporosis & 65 & 71 & 595.5 & 16.4 & $2.05(1.25-3.37)$ & $.004 * *$ \\
\hline & & & & 432.1 & & & \\
\hline \multirow{2}{*}{$\mathrm{BP}$ treatment } & Not during treatment & & 81 & 850.2 & 9.5 & - & \\
\hline & During treatment & & 75 & 492.5 & 15.2 & 1.60 (1.17-2.19) & $.003^{* *}$ \\
\hline \multirow[t]{6}{*}{ Seizure frequency } & Seizure-free & 21 & 7 & 115.5 & 6.1 & - & \\
\hline & Less than 1 a year & 10 & 5 & 71.3 & 7.0 & $1.16(0.37-3.65)$ & .803 \\
\hline & 1 a month to 1 a year & 28 & 26 & 192.8 & 13.5 & $2.23(0.97-5.13)$ & .054 \\
\hline & 1 a week to 1 a month & 49 & 42 & 303.1 & 13.9 & $2.29(1.03-5.09)$ & $.037 *$ \\
\hline & 1 a day to 1 a week & 80 & 62 & 549.4 & 11.3 & $1.86(0.85-4.07)$ & .113 \\
\hline & More than 1 a day & 17 & 14 & 110.8 & 12.6 & $2.09(0.84-5.17)$ & .104 \\
\hline
\end{tabular}

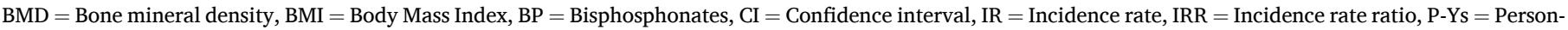
years $* p<.05 * * p<.01$.

Table 4

Multivariate analysis for the risk of fracture during seven years of follow-up in patients with refractory epilepsy and intellectual disability $(n=205)$.

\begin{tabular}{lll}
\hline & Adjusted HR $(95 \% \mathrm{CI})^{\mathrm{a}}$ & $p$ \\
\hline Sex & & \\
Male & 1.00 & .987 \\
Female & $1.00(0.62-1.61)$ & .967 \\
Age & $1.00(0.98-1.02)$ & \\
Mobility & & \\
Able to walk & 1.00 & $<.001^{* *}$ \\
Wheelchair dependent & $0.32(0.16-0.64)$ & .095 \\
BMD (FN) at baseline & $0.19(0.03-1.33)$ & \\
Prevalent VF at baseline & & .181 \\
No & 1.00 & .803 \\
Yes & $1.41(0.85-2.32)$ & .827 \\
Seizure frequency & & .770 \\
Seizure-free & 1.00 & .953 \\
Less than 1 a year & $0.84(0.21-3.40)$ & .835 \\
1 a month to 1 a year & $1.14(0.36-3.61)$ & \\
1 a week to 1 a month & $1.19(0.38-3.69)$ & \\
1 a day to 1 a week & $0.97(0.30-3.15)$ & \\
More than 1 a day & $0.85(0.19-3.91)$ & \\
\hline
\end{tabular}

$\mathrm{BMD}=$ Bone mineral density, $\mathrm{CI}=$ Confidence interval, $\mathrm{FN}=$ Femoral neck, $\mathrm{HR}$ $=$ Hazard ratio, $\mathrm{VF}=$ Vertebral fracture ${ }^{\mathrm{a}}$ Adjusted for age, sex, mobility, BMD of femoral neck at baseline, prevalent VF at baseline and seizure frequency ${ }^{*} p<$ $.05, * * p<.01$.

\section{Discussion}

Over seven years follow-up, $40.0 \%$ of institutionalized adult patients with epilepsy and intellectual disability had suffered from at least one clinical fracture, of whom $38(46.3 \%)$ had at least one MOF. A total of 156 fractures, including $46(29.5 \%)$ major osteoporotic fractures, had been reported during the follow-up period. Fracture risk was significantly lower in patients who were wheelchair dependent as compared to those who were able to walk. In multivariate analyses, no significant differences were found regarding age, sex, seizure frequency, BMD of femoral neck and the presence of a prevalent VF at baseline.

In a large Dutch population-based study in people of 45 years and older, a fracture incidence rate of 2.1 per 100 person-years was found [22]. In our younger study population (mean age $46.8 \pm 16.6$ vs $64.7 \pm$ 9.4 in men and $66.5 \pm 10.9$ in women) the fracture incidence rate was at least five times higher. Schoufour et al. (2015) studied fractures over a three-year follow-up period in patients with intellectual disability aged 50 years and over [23]. Of the 651 patients with complete follow-up data, $97(15 \%)$ sustained one or more fractures, resulting in an IR of at least 5.0 fractures per 100 person-years. Previously published studies in comparable study populations, reported fracture incidences similar to ours, between 7.1 and 14.2 per 100 person-years [11-14]. These studies included institutionalized adult patients with epilepsy, however the degree of mobility and the severity of physical disabilities were underreported and none of these studies reported treatment with bone agents such as bisphosphonates. In addition, these studies were of older age (1977-1999) and did, for that reason, include patients using older (enzyme-inducing) antiseizure drugs, mostly phenobarbital and phenytoin. In our study also newer (non-enzyme-inducing) antiseizure drugs were included, often in polytherapy.

Over the years, several laboratory, preclinical and clinical studies have focused on fracture risk associated with the use of enzyme- vs nonenzyme-inducing antiseizure drugs. Despite numerous attempts to unravel the pathophysiological mechanisms behind the increased fracture risk, these are still not fully understood. It is certain however, that multiple mechanisms exist and that bone mineral disorders are not limited to the use of enzyme-inducing drugs [24,25]. In our study, about three-quarter of the patients used both types of antiseizure drugs and half of all patients had at least one switch in prescribed antiseizure drugs during follow-up. Therefore, we are not able to draw conclusions regarding fracture risk associated with the use of either enzyme- or non-enzyme inducing antiseizure drugs.

Of all seizures that were reported during our study ( $n=169,028)$, at least 39 resulted in a fracture $(0.02-0.1 \%)$. This is comparable to what Nakken et al. (1993) found $(0.1 \%)$ in institutionalized adult patients with intellectual disability and therapy-resistant epilepsy [26]. Note that these studies are probably not very comparable, due to improved techniques in detecting nocturnal seizures which may have increased the number of reported seizures in our study.

As for fracture locations, Grzonka et al. (2019) focused on fractures as a direct consequence of generalized convulsive seizures and/or status epilepticus [27]. Fractures of the shoulders (bilateral; 33\%), thoracic/lumbar vertebrae (29\%), skull/jaw (8\%) and (bilateral) femoral neck $(6 \%)$ were most frequently reported. In our study, these percentages were $7.7 \%, 0 \%, 15.4 \%$ and $7.7 \%$, respectively. None of the 
seizure-related fractures in our patients had been bilateral. In our study, fractures of the lower leg/foot (13/39) and clavicle (9/39) were the most frequently reported seizure-related fracture sites. Some fractures in our study participants may have been the result of a fall, rather than the seizure itself, explaining possible differences in fracture locations as compared to the meta-analysis of Grzonka et al. [27].

Additionally, we would like to consider other causes of falling than seizures. The most common side effects of antiseizure drugs are dizziness and ataxia, resulting in an unsteady gait and impaired balance function $[28,29]$. Additional risk factors for falling in patients with disabilities, are visual impairments, a decreasing physical ability, paretic conditions, impulsiveness, previous falls, incontinence and the non-use of assistive equipment [30]. In our study, almost half of the fractures (45.5\%) had been reported after a fall. In line with the aforementioned factors, we found a lower risk of fractures in patients who were wheelchair dependent than in patients who were able to walk. Based on our findings, we recommend educating caregivers about fracture risks and to raise more awareness about safety measures and fall prevention.

We followed a large group of adult patients with epilepsy over seven years and started (individual) anti-osteoporosis treatment according to the Dutch guidelines. In total, 75 fractures (48.1\%) had occurred during treatment with bisphosphonates. This may raise questions about the effectiveness of the bisphosphonate therapy, but a plausible explanation is that it may reflect the severity of the bone mineral problems in those who receive treatment.

To our knowledge, there are only few studies describing the efficacy of anti-osteoporosis treatment in patients on antiseizure drugs [31-33]. Lazzari et al. (2013) performed a randomized controlled trial in male veterans with epilepsy [31]. Due to ethical reasons, patients with osteoporosis had been excluded. The study group $(n=27)$ received risedronate and the control group $(n=26)$ a matching placebo. During two years of follow-up there had been six MOFs in the placebo group and none in the study group $(p=.023)$. Despite the importance of this research, the results may not be generalizable to other patients with epilepsy, due to the specific in- and exclusion criteria. A less restricted sample was described in the clinical setting of Miller et al. (2020) [32]. They retrospectively reviewed an urban population of patients with epilepsy. All participants $(n=81)$ had two DXA scans at least five years apart (median 9.4 years, range 5-14.7). Eleven patients (13.6\%) had sustained at least one MOF during follow-up, of whom two patients (18.2\%) were prescribed bisphosphonates at their initial DXA scan. Lacking a control group, it is unclear whether anti-osteoporosis treatment influenced the incidence of MOFs. Whitney (2020) adjusted for anti-osteoporosis treatment, by comparing five matched groups ( $n=$ 828 per group) by epilepsy status (with or without) and use of osteoporosis medication (no user, consistent user, or new user) [33]. His-study showed a twelve-month (non-traumatic) fracture risk attenuation in adults with epilepsy who were treated with anti-osteoporosis medication, especially in those who just started treatment.

In our study, we cannot draw conclusions about the efficacy of bisphosphonates on fractures, as it was ethically not justified to form a control group within our cohort. With regards to safety; two reported adverse effects of long-term bisphosphonate therapy are osteonecrosis of the jaw and atypical subtrochanteric femoral fractures [34]. To our knowledge, none of our study participants had suffered from these side effects.

\subsection{Limitations}

Although all our patients live in a sheltered and relatively safe environment, we observed a total of 156 fractures in 82 patients. Overall, this number might be underestimated for several reasons. Patients who were lost to follow-up were significantly older than patients who completed follow-up, which may probably have resulted in underestimation. In addition, it can be difficult to diagnose fractures in patients with severe physical deformities or in patients who are unable to lie still for diagnostics. Patients are not always referred to the hospital when suspecting a fracture. For example, when there are no treatment options (e.g. a well-positioned nose fracture without obstruction of the airway) or when the fracture is considered as minor and does not affect physical outcome (e.g. a fractured toe or metatarsal bone in a patient who is not able to stand or walk). In those cases, a visit to the hospital results in a high burden and a lot of stress and does not lead to any benefit for the patient itself. Since we have only included radiographically verified fractures, these fractures are not accounted for in this study. Also, patients may not be able to indicate pain or discomfort caused by a fracture due to poor intellectual and/or verbal capacities. In these (more disabled) patients, minor fractures may not have been recognized. All the above-mentioned reasons could have led to an underestimation of the real fracture incidence. Due to the severity and the impact, we do believe that no major osteoporotic fractures had been missed during follow-up of the patients in our study.

Information regarding the circumstances and/or cause of the fracture was missing in some patients. In those cases, we were not able to differentiate between fractures caused by trauma or seizures. Fractures of unknown causes in our study, may have been the result of an unwitnessed trauma or seizure.

\section{Conclusion}

This study demonstrated that $40 \%$ of institutionalized adults with epilepsy and intellectual disability had at least one clinical fracture during seven years of follow-up, despite anti-osteoporosis treatment according to the Dutch guidelines. The use of (multiple) antiseizure drugs is known to decrease bone mineral density and increase fracture risk. In our study, at least $70 \%$ of the fractures had been caused by a fall and/or seizure. In addition to seizure reduction, it is essential to have a focus on fall prevention. Physical disabilities, comorbidity, behavioral issues and drug side effects might increase the risk of falling, especially in patients who are able to walk. This study emphasizes the complex and multifactorial nature of fractures in patients with epilepsy and intellectual disability. These patients already suffer from multiple physical disabilities and are mainly dependent on others for their daily living. Fractures have a high impact on their quality of life. Even unrecognized, fractures may cause pain, discomfort and further limit daily activities. In order to prevent fractures in this specific group, more research is needed to establish optimal treatment options.

\section{Declaration of interest}

$\mathrm{JvdB}$ has received research funding from UCB and Amgen not related to the work presented in this paper. The remaining authors have no conflicts of interest to disclose.

\section{Funding}

This research did not receive any specific grant from funding agencies in the public, commercial, or not-for-profit sectors.

\section{Declaration of Competing Interest}

The authors declare that they have no known competing financial interests or personal relationships that could have appeared to influence the work reported in this paper.

\section{References}

[1] WHO. Epilepsy. http://www.who.int/en/news-room/fact-sheets/detail/epilepsy; 2019.

[2] Dent CE, Richens A, Rowe DJ, Stamp TC. Osteomalacia with long-term anticonvulsant therapy in epilepsy. Br Med J 1970;4:69-72. https://doi.org/ 10.1136/bmj.4.5727.69. 
[3] Hahn TJ. Bone complications of anticonvulsants. Drugs 1976;12:201-11. https:// doi.org/10.2165/00003495-197612030-00003.

[4] Linde J, Molholm Hansen J, Siersbaek-Nielsen K, Fuglsang-Fredriksen V. Bone density in patients receiving long-term anticonvulsant therapy. Acta Neurol Scand 1971;47:650-1. https://doi.org/10.1111/j.1600-0404.1971.tb07517.x.

[5] Shen C, Chen F, Zhang Y, Guo Y, Ding M. Association between use of antiepileptic drugs and fracture risk: a systematic review and meta-analysis. Bone 2014;64: 246-53. https://doi.org/10.1016/j.bone.2014.04.018.

[6] Vestergaard P. Epilepsy, osteoporosis and fracture risk - a meta-analysis. Acta Neurol Scand 2005;112:277-86. https://doi.org/10.1111/j.16000404.2005.00474.x.

[7] Henderson RC, Lark RK, Gurka MJ, Worley G, Fung EB, Conaway M, et al. Bone density and metabolism in children and adolescents with moderate to severe cerebral palsy. Pediatrics 2002;110:e5. https://doi.org/10.1542/peds.110.1.e5.

[8] Jaffe JS, Timell AM, Elolia R, Thatcher SS. Risk factors for low bone mineral density in individuals residing in a facility for the people with intellectual disability. J Intellect Disabil Res 2005;49:457-62. https://doi.org/10.1111/j.13652788.2005.00700.x.

[9] Sharawat IK, Sitaraman S. Skeletal maturation and mineralisation of children with moderate to severe spastic quadriplegia. J Clin Diagn Res 2016;10:Sc01-5. https:// doi.org/10.7860/jcdr/2016/18620.7921.

[10] Tosun A, Erisen Karaca S, Unuvar T, Yurekli Y, Yenisey C, Omurlu IK. Bone mineral density and vitamin D status in children with epilepsy, cerebral palsy, and cerebral palsy with epilepsy. Childs Nerv Syst 2017;33:153-8. https://doi.org/10.1007/ s00381-016-3258-0.

[11] Desai KB, Ribbans WJ, Taylor GJ. Incidence of five common fracture types in an institutional epileptic population. Injury 1996;27:97-100.

[12] Lidgren L, Walloe A. Incidence of fracture in epileptics. Acta Orthop Scand 1977; 48:356-61.

[13] Lohiya GS, Crinella FM, Tan-Figueroa L, Caires S, Lohiya S. Fracture epidemiology and control in a developmental center. West J Med 1999;170:203-9.

[14] Nilsson OS, Lindholm TS, Elmstedt E, Lindbäck A, Lindholm TC. Fracture incidence and bone disease in epileptics receiving long-term anticonvulsant drug treatment. Arch Orthop Trauma Surg 1986;105:146-9. https://doi.org/10.1007/bf00433931.

[15] Beerhorst K, Tan J, Tan IY, Verschuure P, Aldenkamp AP. Dual-energy X-ray absorptiometry versus quantitative ultrasonography in diagnosing osteoporosis in patients with refractory epilepsy and chronic antiepileptic drug use. Ther Adv Musculoskelet Dis 2013;5:59-66. https://doi.org/10.1177/1759720 × 13475851 .

[16] Beerhorst K, Tan IY, de Krom M, Verschuure P, Aldenkamp AP. Antiepileptic drugs and high prevalence of low bone mineral density in a group of inpatients with chronic epilepsy. Acta Neurol Scand 2013;128:273-80. https://doi.org/10.1111/ ane.12118.

[17] Kanis JA. Assessment of fracture risk and its application to screening for postmenopausal osteoporosis: synopsis of a WHO report. WHO Study Group. Osteoporos Int 1994;4:368-81. https://doi.org/10.1007/bf01622200.

[18] Kanis JA, Johansson H, Harvey NC, McCloskey EV. A brief history of FRAX. Arch Osteoporos 2018;13:118. https://doi.org/10.1007/s11657-018-0510-0.

[19] Berkvens J, Majoie M, Mergler S, Beerhorst K, Verschuure P, Tan I, et al. Prevalence and incidence of vertebral fractures: a 7-year follow-up study in institutionalized adults with refractory epilepsy and intellectual disability. Epilepsy Res 2020;167:106461. https://doi.org/10.1016/j.eplepsyres.2020.106461.

[20] CBO. Richtlijn Osteoporose. Tweede herziening. 2002.

[21] СВO. Richtlijn Osteoporose en fractuurpreventie. Derde herziening. https://volks gezondheidenzorg.info/bestanden/documenten/cbo-richtlijn-osteoporose-en-frac tuurpreventie-2011; 2011.

[22] Trajanoska K, Schoufour JD, de Jonge EAL, Kieboom BCT, Mulder M, Stricker BH, et al. Fracture incidence and secular trends between 1989 and 2013 in a population based cohort: the Rotterdam Study. Bone 2018;114:116-24. https://doi.org/ 10.1016/j.bone.2018.06.004.

[23] Schoufour JD, Echteld MA, Bastiaanse LP, Evenhuis HM. The use of a frailty index to predict adverse health outcomes (falls, fractures, hospitalization, medication use, comorbid conditions) in people with intellectual disabilities. Res Dev Disabil 2015;38:39-47. https://doi.org/10.1016/j.ridd.2014.12.001.

[24] Diemar SS, Sejling AS, Eiken P, Andersen NB, Jörgensen NR. An explorative literature review of the multifactorial causes of osteoporosis in epilepsy. Epilepsy Behav 2019;100:106511. https://doi.org/10.1016/j.yebeh.2019.106511.

[25] Fan HC, Lee HS, Chang KP, Lee YY, Lai HC, Hung PL, et al. The Impact of AntiEpileptic Drugs on Growth and Bone Metabolism. Int J Mol Sci 2016;17. https:// doi.org/10.3390/ijms17081242.

[26] Nakken KO, Lossius R. Seizure-related injuries in multihandicapped patients with therapy-resistant epilepsy. Epilepsia 1993;34:836-40.

[27] Grzonka P, Rybitschka A, de Marchis GM, Marsch S, Sutter R. Bone fractures from generalized convulsive seizures and status epilepticus-A systematic review. Epilepsia 2019;60:996-1004. https://doi.org/10.1111/epi.14738.

[28] Fife TD, Sirven J. Antiepileptic drugs and their impact on balance. Aging health 2005; 1:147-55.

[29] Petty SJ, Hill KD, Haber NE, Paton LM, Lawrence KM, Berkovic SF, et al. Balance impairment in chronic antiepileptic drug users: a twin and sibling study. Epilepsia 2010;51:280-8. https://doi.org/10.1111/j.1528-1167.2009.02254.x.

[30] Pope J, Truesdale M, Brown M. Risk factors for falls among adults with intellectual disabilities: a narrative review. J Appl Res Intellect Disabil 2021;34:274-85. https://doi.org/10.1111/jar.12805.

[31] Lazzari AA, Dussault PM, Thakore-James M, Gagnon D, Baker E, Davis SA, et al. Prevention of bone loss and vertebral fractures in patients with chronic epilepsy-antiepileptic drug and osteoporosis prevention trial. Epilepsia 2013;54: 1997-2004. https://doi.org/10.1111/epi.12351.

[32] Miller AS, Ferastraoaru V, Tabatabaie V, Gitlevich TR, Spiegel R, Haut SR. Are we responding effectively to bone mineral density loss and fracture risks in people with epilepsy? Epilepsia Open 2020;5:240-7. https://doi.org/10.1002/ epi4.12392.

[33] Whitney DG. Effectiveness of osteoporosis medication on site-specific fracture-risk attenuation among adults with epilepsy. Epilepsia 2020;61:2583-92. https://doi. org/10.1111/epi.16700.

[34] Kennel KA, Drake MT. Adverse effects of bisphosphonates: implications for osteoporosis management. Mayo Clin Proc 2009;84:632-7. https://doi.org/ 10.1016/s0025-6196(11)60752-0. quiz 638. 